\title{
2687. Survey on the influencing factors of human comfort in a long-period frequent blast vibration environment
}

\author{
Qiang Yao ${ }^{1}$, Xingguo Yang ${ }^{2}$, Hongtao $\mathrm{Li}^{3}$ \\ State Key Laboratory of Hydraulics and Mountain River Engineering, Sichuan University, \\ Chengdu, Sichuan, 610065, China \\ College of Water Resource and Hydropower, Sichuan University, Chengdu, Sichuan, 610065, China \\ ${ }^{3}$ Corresponding author \\ E-mail: 1yaoqiang777@126.com, ${ }^{289022251 @ 163 . c o m,{ }^{3} h t l @ s c u . e d u . c n}$
}

Received 18 January 2017; received in revised form 4 May 2017; accepted 26 June 2017

DOI https://doi.org/10.21595/jve.2017.18192

Abstract. Blasting operation exerts adverse effects on the vibration comfort of nearby buildings and structures, and causes a number of civil complaints, discomfort and even lawsuits. Blasting vibration comfort is related not only to the vibration characteristics of blasting and buildings, but also to the non-blasting factors such as, (i) the gender, age, income, psychology, and educational background of the subjects, (ii) the environment they are in, and (iii) the activities in which they are engaged. Based on typical multi-year frequent blasting work cases, three groups of people are selected, and Likert scale method is used to design a detailed comfort survey plan. After tracking, monitoring and surveying over several years, 168 groups of survey data are obtained. The survey results show that, there is a nonlinear relationship between human comfort and blasting vibration amplitude. Moreover, compared with the peak particle vibration velocity (PPV), the absorbed blasting vibration energy (ABVE) index can better reflect the influence of blasting vibration factors. Difference in human comfort between different groups of people and its causes are analyzed. The correlation analysis results show that the correlation coefficients between vibration comfort and four factors (blasting noise, environmental noise, environmental vibration and ongoing activities) range from 0.28 to 0.34 . Finally, combining the statistical analysis results, six factors exerting a relatively significant influence on comfort are determined. The outcomes are expected to provide a basis for eventually establishing a multi-level and multi-factor quantitative evaluation model for blasting vibration comfort.

Keywords: blasting vibration, comfort, fuzziness, field survey, likert scale, non-blasting vibration factor.

\section{Introduction}

Blasting vibration comfort is an emerging inter-disciplinary issue that involves mechanics of explosion, dynamics of structures, statistics, psychology, and information processing, biological dynamics and so on. It reflects the evaluation of the comfort experienced by human body against blasting vibration effects. As there are increasing numbers of projects on hydropower engineering, railway construction, highway construction and urban construction, the blasting work around human habitations is also increasing every day, as is the number of civil disputes, complaints and lawsuits incurred by the blasting vibration effect resulting from blasting work $[1,2]$. Human body is very sensitive to the vibration caused by the earth and atmospheric disturbances as a result of blasting work; the degree of sensitivity is approximately ten times of that of buildings and structures $[3,4]$. Since the vibration strength that satisfies structural safety can still cause human discomfort, the complaints and disputes cannot be solved only from the perspective of structural safety [5]. Surveys and research have shown that the nature of most cases is an overreaction on the part of local people to blasting vibration when they and their property are exposed to the threat of blasting vibration. Their complaints, discomfort and even lawsuits are mainly caused by the annoyance with blasting work, the worry about structural failure and the disturbance effect. This is a typical vibration comfort issue, rather than safety issue [6-8]. In recent years, blasting vibration 
comfort has raised wide attention in the United States, Canada, the United Kingdom, India, China, etc. [9-14]. The problem, as many researchers put it, has evolved from the problem of structural damage to that of how to reduce lawsuits. The sensitivity of people to vibration is an important aspect $[5,15]$ and it has become a new research topic [16-17].

The reaction of human body to blasting vibration is influenced by a series of factors, such as vibration amplitude, frequency and duration [6, 18-20] Currently, the widely adopted indices in evaluating blasting vibration comfort mainly include peak strength of blasting vibration, maximum weighted vibration intensity $K B_{F \max }$, quadric vibration dose value VDV, and annoyance rate index [21-22]. These indices are established in consideration of a single factor under blasting vibration. As a result, they all exhibit some deficiency, and may lead to different or even contradictory conclusions about the comfort evaluation in practice [8, 14]. The phenomenon of contradictory results can be explained from two aspects: firstly, current evaluation standards on vibration comfort mainly focus on the steady state vibration such as mechanical vibration, and there is still a lack of definite evaluation standards on the transient impact vibrations such as blasting; and secondly, since blasting vibration is different from mechanical vibration and poses a higher threat to safety, different people, under the influence of different attitudes, mental states, wealth levels, social environments and so forth, usually react differently to the same vibration effect, showing some fuzziness and uncertainty. Moreover, when a certain value of an index is adopted as the threshold of comfort or discomfort, it only provides a qualitative evaluation, as it fails to differentiate the degree of discomfort among the public and on the environment. Thus, use of such indices is insufficient to quantitatively evaluate human comfort. In practical cases, due to vibration-induced earthquake and other negative effects (like blasting noise) as well as the involvement of several parties, quantitative analysis of blasting comfort is difficult.

Research on the vibration comfort, the theory of literature from the point of view at home and abroad, mainly focus on the vibration comfort in the vehicle and buildings etc., and research in the areas of blast vibration is also less. Parkin, Wang, Nakagawa, Sezgin and Kolich [23-29] studied from the survey of cycle users which investigates potential comfort and health factors resulting from cycling, and found that comfort is a subjective construct, and jury evaluations administered in the form of surveys were the best way to understand customer/consumer perceptions and expectations of comfort. Johann, et al. [30] studied comfort performance during wind-induced motions and found several criteria concerning comfort evaluation were not agreed between different authors and different normative codes, and the users must be aware of the building motions and educated to cope with it in the future in comfort evaluation. In the perception of vibration in buildings, theoretical and empirical models and measurement procedures were devoted to define and quantify objective and subjective responses to external stimuli on human, on the basis of several aspects (e.g. annoyance, physiological and psychological effects, behavioral effects) [31]. Lusk [32-34] utilized Likert Scaled Surveys to determine residents' comfort levels with different air blast reporting units including dBs, millibars and pounds per square inch (PSI). And found that using surveys to establish baseline communication levels with neighbors could advance public relations for mining operations by providing insight and direction for site specific public relations programs. Maeda, et al. [35] conducted the questionnaires distributed to 33 wheelchair users directly by the experimenter in order to identify the causes of complaints from wheelchair vibrations that they experienced. Khan and Sundström [36] studied three hundred thirty Swedish passengers using a questionnaire survey on vibration comfort in Swedish Inter-City Trains. Mirzaei and Mohammadi [37] studied vibration exposure of tractor drivers and assessment of musculoskeletal disorder using Nordic questionnaire. Rudenko, Siebert and Singh [38-40] studied the perceptions of the use of explosives and the analytical approach for diagnosing and solving blasting complaints. Deros et al. [41] found that subjective perception depends on demographic background factors very much. Hendron and Oriard [42] compared human reactions to vibration noise under pulses and proved blasting noise as the main factor influencing human comfort. Raina [12] surveyed the reactions of residents nearby mining areas 
during blasting work and found that blasting vibration and noise were the main factors that influenced the surrounding environment of mining areas. When the fundamental interests of residents were threatened, their real reactions would be intensified. Survey results showed that the attitudes of residents to blasting vibration depended on age, gender, educational background and income [43].

To sum up, when evaluating blasting vibration comfort, various harmful effects (such as vibration and noise) exerted by blasting should be fully considered; then, with reference to the evaluation results for the majority of residents (the largest number of population with similar age, educational background, income, gender and social environment in the total population) living around the blasting source, real and reasonable comfort evaluation conclusions are obtained [1]. This paper conducts a number of surveys on blasting vibration comfort based on several blasting projects, performs a comprehensive and systematic analysis on non-blasting vibration factors influencing human comfort, and finally determines the main influencing factors. The findings are expected to provide a basis for establishing a multi-level and multi-factor quantitative evaluation model for blasting vibration comfort.

\section{Absorbed blasting vibration energy (ABVE)}

The human body is not only affected by the blasting vibration intensity, but also by the vibration frequency, duration and other dynamic factors. In this study, the effect of blasting vibration on people is considered as an energy transfer and conversion. Blasting is energy source, blasting seismic waves can be considered as energy carriers, and a human body inside a building can be treated as an energy acceptor. The final reaction of a human body can be seen as the reaction results of the receptor. Under certain input and deformation conditions, the body can be regarded as a linear system. A linear parameter centralized system can be used to approximate a vibration system consisting of lifeless mass, flexible and damping elements. Different body part has its own vibration frequency. When the blasting seismic waves are transmitted to the floor or seats that are in contact with the body, the vibration energy is absorbed into the body, and the energy is transmitted along the body. The energy transfer and conversion concepts can be used to evaluate the vibration characteristics of the human body, which is referred to as the "Absorbed Blasting Vibration Energy (ABVE)" [44]. The ABVE can be used as a parameter to characterize the interaction between humans and the vibration environment. Based on the assumptions of human energy transmission and absorption, the absorbed blasting vibration energy per unit time can be described by the power, and the mechanical simulation of power can be measured by their work. As absorbed energy is a measure of the dissipated energy input by the vibration, and the absorbed energy by the body during time $T$ can be expressed as:

$E=\int_{0}^{T} F(t) \cdot V(t) d t$,

where $E$ is the absorbed energy by the body; $F(t)$ is a function of the input force; and $V(t)$ is a function of the input speed.

In a blasting vibration comfort evaluation, mainly only the kinetic vibration energy is considered. The absorbed blasting vibration energy at a given time can be represented by the squared vibration velocity at that time. As the monitored blasting vibration velocity is generally a discrete digital signal, the Eq. (1) can be rewritten as:

$E=\left(\sum_{i=1}^{i=n} v^{2}\left(t_{i}\right)\right) * \Delta t$.

In Eq. (2), $v\left(t_{i}\right)$ is the discrete digital signal of blasting vibration velocity; $n$ is the total 
number of samples; $\Delta t$ is the sampling interval.

The total blasting vibration energy $E$ accounts for the change in energy over time without including the effect of frequency. The power spectral density $P S D(f)$ can describe the relative magnitude of the harmonic component energy within a certain frequency range. Based on the spectral analysis on the blasting vibration velocity, different frequency bands $f_{i}$ and the corresponding power spectral density $P S D_{i}$ can be determined. Then, the ratio of the energy in any one of the frequency bands $\left(f_{m} \leq f<f_{n}\right)$ to the total energy is:

$P_{E_{f}}=\frac{\sum_{i=m}^{n-1} P S D_{i}}{\sum P S D_{i}}$

where $P_{E_{f}}$ is the proportion of the energy within the frequency range $f_{m} \leq f<f_{n}$ in the total energy.

After determining the blasting vibration energy from Eq. (2), the absorbed blasting vibration energy within each frequency range can be determined from Eq. (3).

Therefore, after the spectral analysis of the blasting vibration signal, the entire frequency domain has been segmented. Combining Eqs. (2-4), the energy ratio and magnitude in each frequency band and the total absorbed blasting vibration energy can be determined:

$E_{f}=P_{E_{f}} \cdot E$.

\section{Survey on blasting vibration comfort}

\subsection{Determination of survey respondents}

Blasting vibration monitoring and comfort survey were conducted on the surface blasting and excavation activities of two hydropower stations \#1 and \#2, as shown in Fig. 1 and Fig. 2. Hydropower station $1 \#$ is located in a canyon reach. One side of the construction site is comprised of a steep mountain, while the other side is comprised of a relatively flat and highly populated ground. Therefore, the blasting and excavation face is directly opposite to the population settlement on the other side of the river. The left bank slope of the hydropower station and the blasting construction regions (such as the workshop and the tailrace outlet slope) are separated by a river from the densely populated area (Area A) on the opposite bank. The minimum horizontal distance between the blasting face and the settlement (Area A) is approximately $100 \mathrm{~m}$, while that to the further settlements (Area B and C) is approximately $200 \mathrm{~m}$.

As shown in Fig. 2, hydropower station 2\# is located close to a highway, passing through a settlement (Area D). The settlement is only 50-80 m away from the blasting and excavation area of dam foundation. Depending on the survey areas and respondents, the blasting vibration monitoring and comfort survey areas were classified into five areas, i.e., Areas A, B1, B2, C and $\mathrm{D}$, as shown in Fig. 1 and Fig. 2. Considering that the above two engineering blasting work areas are densely populated and that the blasting environment is complicated, during construction, efforts should be made to prevent damages to residents' houses. Moreover, the frequent blasting work should be controlled from influencing or incurring mass disturbances.

Construction of the hydropower projects involved frequent blasting operations occurring for several years. Therefore, the local government set up a special "Immigration Headquarters for Engineering Construction", one task of which was to coordinate the relationship between blasting units and nearby residents, and mediate in cases of complaints and disputes. In the early days of blasting construction, there were dissatisfactions and disputes on the part of some residents in both projects. The major concerns were significant house vibration, wall cracking, and being terrified. By analyzing the occurrence times and locations of disputes and the corresponding monitored data of blasting vibration and noise, it was found that the vibration strength was not necessarily the 
largest when the reactions of residents were the strongest, and that, when the vibration strength was the largest, the reactions of residents were not markedly strong. This indicates that the magnitude of blasting vibration was not the only factor influencing the reaction of residents. In order to clarify the main factors that influenced blasting vibration comfort, the blasting vibration comfort was surveyed and studied in addition to massive blasting vibration monitoring. The results showed that under many circumstances, it was hard for respondents to clearly distinguish the magnitude of vibration. Human feelings were affected by several factors as additional to blasting vibration. Thus, there was a nonlinear relationship between the human comfort and the blasting vibration magnitude.

The blasting vibration was continuously monitored particularly for the settlements near blasting faces. Seventeen monitoring points were arranged as, five in Area B1 and Area B2, ten in Area A, and two in Area C. Monitoring instrument at all locations was laid out near the level of building foundation. One to two residents were selected as respondents around each monitoring point. Since human comfort is related to gender, age, income, educational background and many other factors, respondents were selected carefully to obtain adequately reliable and representative survey results. First, the respondents were preliminarily filtered to remove as many interfering factors (such as economic benefit) as possible; then the majority of residents around the blasting work site (the largest number of population with similar gender, age, income, educational background and social environment in the total population) were selected as primary respondents.

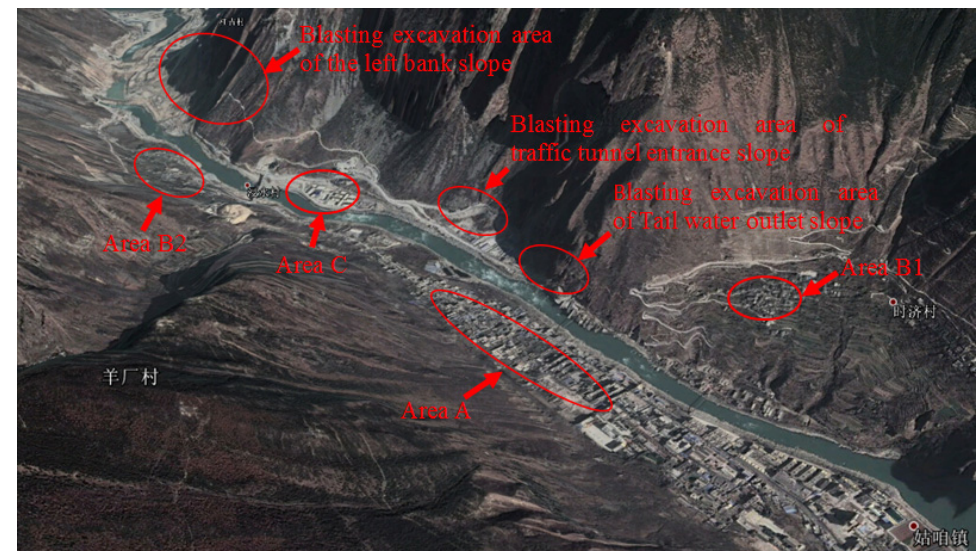

Fig. 1. The distribution of blasting operation area and residential area of hydropower station \#1

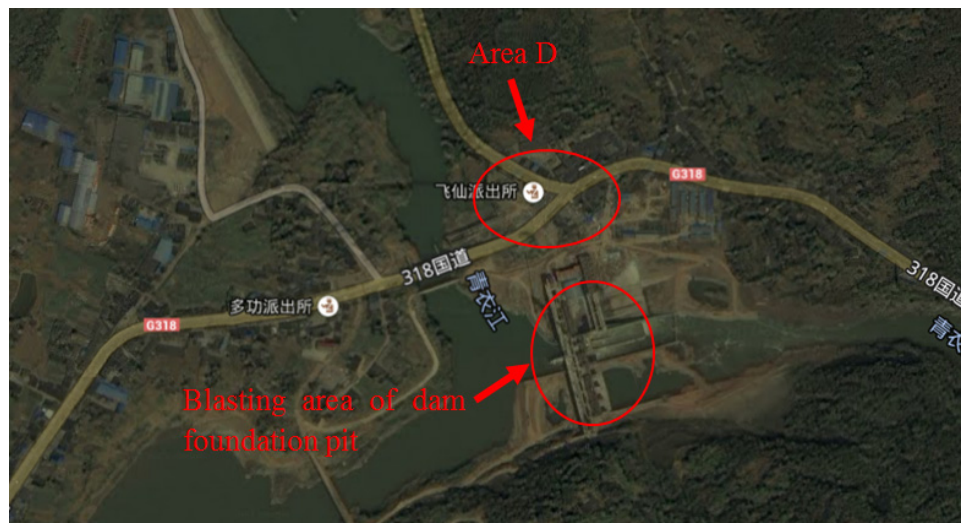

Fig. 2. The distribution of blasting operation area and residential area of hydropower station \#2

Three groups of people were surveyed in this paper, they were, local residents near the blasting site, constructors who were not engaged in blasting work and residents who were going to move. 
As shown in Fig. 2 to Fig. 6, respondents in Area A, Area B1 and Area B2 were local residents near the blasting site, while those in Area $\mathrm{C}$ were constructors who were not engaged in blasting work, and those in Area D were residents who are going to move. Local residents had little contact with blasting work and lacked professional knowledge in this aspect. Combined with the annoyance and disturbance effect incurred by blasting work and their worry about the structural failure of their houses, they were more sensitive to blasting work and usually had much stronger reactions. Constructors who were not engaged in blasting work had different reactions since they usually had frequent contact with blasting work and did not need to worry about the structural failure (they were not owners of any house). As for those residents who were going to move, they did not need to worry about the damage to their houses or buildings. However, since they also had little contact with blasting work and lacked professional knowledge, they also had different feelings. Analysis of the differences in feelings of the three different populations helped in clarifying the influence of various factors on comfort, such as whether respondents were house owners or not, and whether they had prior experience of blasting work. The analysis further helped in investigating the reasons of different attitudes of different populations to the same blasting work and in understanding and solving the obstacles in proper communication. For instance, since differences in the understanding and feelings about the blasting work existed between the construction units of blasting work and the local residents, various irreconcilable contradictions and disputes would occur, which would be both unfavorable for engineering construction and social stability.

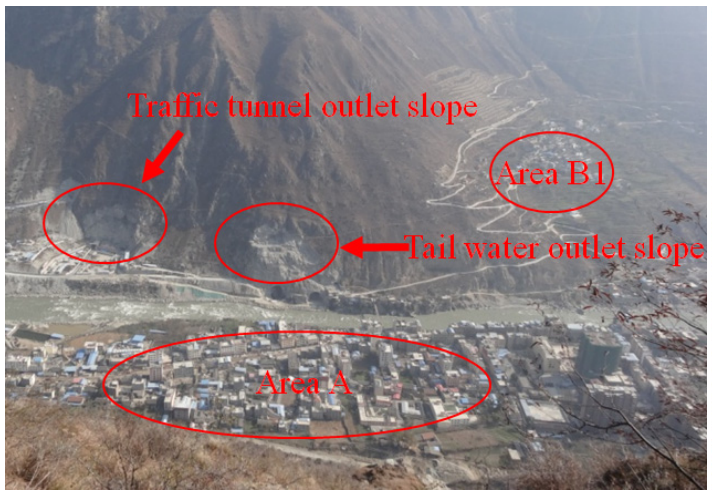

Fig. 3. Area $A$ and area B1 and surrounding blasting operation area

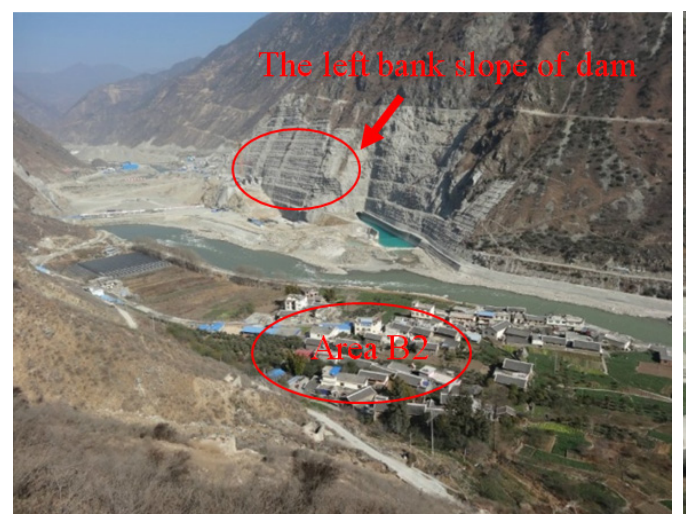

Fig. 5. Area B2 and surrounding blasting operation area

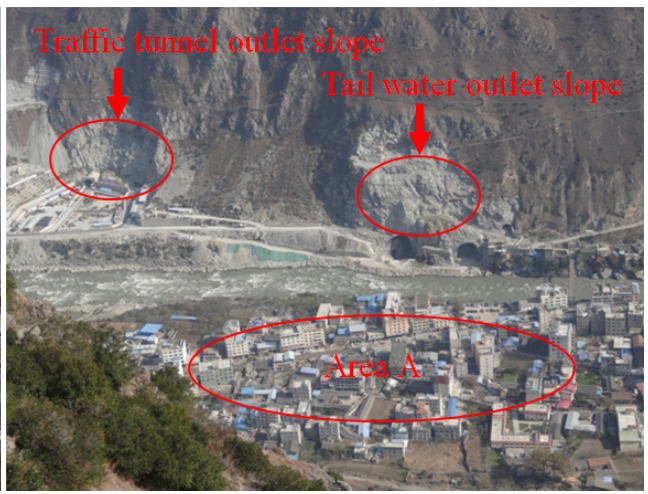

Fig. 4. Area A and surrounding blasting operation area

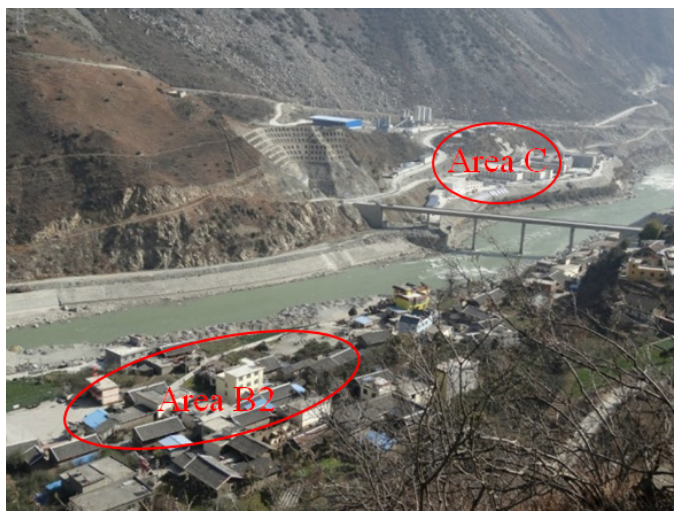

Fig. 6. Area $\mathrm{C}$ and surrounding blasting operation area 
Table 1. Basic statistics of the object being investigated

\begin{tabular}{|c|c|c|c|c|c|c|c|}
\hline $\begin{array}{l}\text { The } \\
\text { numbers }\end{array}$ & Gender & Age & Occupation & Health & Education & $\begin{array}{l}\text { Whether or not } \\
\text { previously exposed to } \\
\text { blasting vibration }\end{array}$ & $\begin{array}{c}\text { Whether or not } \\
\text { the owner of the } \\
\text { house }\end{array}$ \\
\hline 1 & Male & 36 & Farmer & Good & $\begin{array}{l}\text { Junior high school } \\
\text { graduation }\end{array}$ & Not & Yes \\
\hline 2 & Female & 54 & $\begin{array}{c}\text { Self- } \\
\text { employed }\end{array}$ & Good & $\begin{array}{c}\text { Primary school } \\
\text { graduation }\end{array}$ & Not & Yes \\
\hline 3 & Male & 41 & $\begin{array}{c}\text { Self- } \\
\text { employed }\end{array}$ & Good & $\begin{array}{c}\text { Junior high school } \\
\text { graduation }\end{array}$ & Not & Yes \\
\hline 4 & Male & 31 & $\begin{array}{c}\text { Self- } \\
\text { employed }\end{array}$ & Good & $\begin{array}{l}\text { High school } \\
\text { graduation }\end{array}$ & Not & Yes \\
\hline 5 & Male & 62 & Farmer & Good & $\begin{array}{l}\text { Junior high school } \\
\text { graduation }\end{array}$ & Not & Yes \\
\hline 6 & Female & 28 & Farmer & Good & $\begin{array}{l}\text { High school } \\
\text { graduation }\end{array}$ & Not & Yes \\
\hline 7 & Female & 30 & $\begin{array}{c}\text { Self- } \\
\text { employed }\end{array}$ & Good & $\begin{array}{c}\text { Junior high school } \\
\text { graduation }\end{array}$ & Not & Yes \\
\hline 8 & Male & 63 & $\begin{array}{c}\text { Self- } \\
\text { employed }\end{array}$ & Good & $\begin{array}{c}\text { Primary school } \\
\text { graduation }\end{array}$ & Not & Yes \\
\hline 9 & Female & 27 & Farmer & Good & $\begin{array}{l}\text { High school } \\
\text { graduation }\end{array}$ & Not & Yes \\
\hline 10 & Female & 35 & $\begin{array}{c}\text { Self- } \\
\text { employed }\end{array}$ & Good & $\begin{array}{l}\text { High school } \\
\text { graduation }\end{array}$ & Not & Yes \\
\hline 11 & Male & 45 & Farmer & Good & $\begin{array}{l}\text { Primary school } \\
\text { graduation }\end{array}$ & Not & Yes \\
\hline 12 & Male & 27 & $\begin{array}{c}\text { Self- } \\
\text { employed }\end{array}$ & Good & $\begin{array}{c}\text { Graduated from } \\
\text { college }\end{array}$ & Not & Yes \\
\hline 13 & Female & 42 & Farmer & Good & $\begin{array}{c}\text { Graduated from } \\
\text { technical secondary } \\
\text { school }\end{array}$ & Not & Yes \\
\hline 14 & Female & 58 & Farmer & Good & $\begin{array}{c}\text { Primary school } \\
\text { graduation }\end{array}$ & Not & Yes \\
\hline 15 & Male & 25 & Farmer & Good & $\begin{array}{c}\text { Graduated from } \\
\text { college }\end{array}$ & Not & Yes \\
\hline 16 & Male & 55 & $\begin{array}{c}\text { Self- } \\
\text { employed }\end{array}$ & Good & $\begin{array}{c}\text { Junior high school } \\
\text { graduation }\end{array}$ & Not & Not \\
\hline 17 & Male & 65 & Farmer & Good & $\begin{array}{c}\text { Junior high school } \\
\text { graduation }\end{array}$ & Not & Not \\
\hline 18 & Female & 47 & Farmer & Good & $\begin{array}{c}\text { Graduated from } \\
\text { technical secondary } \\
\text { school }\end{array}$ & Not & Not \\
\hline 19 & Female & 68 & Farmer & Good & $\begin{array}{c}\text { Primary school } \\
\text { graduation }\end{array}$ & Not & Not \\
\hline 20 & Male & 25 & Farmer & Good & $\begin{array}{l}\text { Graduated from } \\
\text { college }\end{array}$ & Not & Not \\
\hline 21 & Female & 28 & Engineer & Good & University graduated & Yes & Not \\
\hline 22 & Male & 33 & Engineer & Good & $\begin{array}{c}\text { Graduated from } \\
\text { college }\end{array}$ & Yes & Not \\
\hline 23 & Female & 31 & Engineer & Good & University graduated & Yes & Not \\
\hline 24 & Male & 27 & Engineer & Good & $\begin{array}{c}\text { Graduated from } \\
\text { college }\end{array}$ & Yes & Not \\
\hline 25 & Male & 30 & Engineer & Good & $\begin{array}{l}\text { Graduated from } \\
\text { college }\end{array}$ & Yes & Not \\
\hline
\end{tabular}




\subsection{Design of survey plan}

After determining the survey areas and population, the next step was to select the sampling method. In this paper, purposive sampling, also known as judgment sampling, was selected from the non-probability sampling methods. The method involves selecting those respondents which are judged as the most representative of the population. This sampling method is mostly used when the population boundary cannot be precisely defined or the researchers have limited time, human power or material resources, thus suitable for solving the problem explored in this paper. Based on the results of the blasting vibration comfort evaluation, the respondents were determined as the majority of residents around the blasting work site (the largest number of population with similar gender, age, income, educational background and social environment in the total population). Their ages ranged from 25 to 60 years, and many of them were the core of a family, thus, more concerned with the blasting work. The main respondents determined in this paper are shown in Table 1.

Design of a survey plan is of great importance for final survey results. The survey can be conducted by telephone, verbal query or questionnaire, among which the last was adopted in this paper. Questions in the questionnaire were kept consistent for different respondents. Before the survey began, the following preparatory work was done according to Walonick's conclusions [45-46]:

(1) Determine the potential respondents that were the most likely potential respondents, and make it clear that the questionnaire was only for research purpose and involved no economic benefit or compensation (except some remuneration);

(2) Provide respondents with final questionnaire, and tell them the meaning of each question and answer, and that they should faithfully finish the questionnaire after the blasting work;

(3) Train respondents before the survey, so that they could make full sense of the nature and purpose of the subjective survey, and could take the questions proposed by the investigator seriously so that the questions could be explained and/or modified if necessary to eliminate any confusion.

Table 2. Evaluation of blasting vibration comfort

\begin{tabular}{|c|c|c|c|c|c|c|c|c|c|c|}
\hline Name & Gender & $\mathrm{Ag}$ & Occupation & \multicolumn{2}{|c|}{ Health } & \multicolumn{2}{|c|}{ Education } & $\begin{array}{c}\text { Whether or not } \\
\text { previously } \\
\text { exposed to } \\
\text { blasting } \\
\text { vibration }\end{array}$ & $\begin{array}{l}\text { Whether or } \\
\text { not the } \\
\text { owner of } \\
\text { the house }\end{array}$ & $\begin{array}{l}\text { Which } \\
\text { floor is } \\
\text { located }\end{array}$ \\
\hline \multicolumn{11}{|c|}{ 1. The feeling of blasting noise } \\
\hline 1.1 & Very serio & & 2. Seri & & & 3. Or & linary & 4. Not serious & 5. Very no & serious \\
\hline \multicolumn{11}{|c|}{ 2. Environmental noise } \\
\hline & Very quic & & 2. Qu & & & 3. Or & linary & 4. Noisy & 5. Very & noisy \\
\hline \multicolumn{11}{|c|}{ 3. Environmental vibration } \\
\hline & Very quic & & 2. Qu & & & 3. Or & linary & 4. Strong & 5. Very & trong \\
\hline \multicolumn{11}{|c|}{ 4. Ongoing activities } \\
\hline $\begin{array}{r}\text { 1. S } \\
\text { (Note } \\
\text { vibratio } \\
\mathrm{h}\end{array}$ & $\begin{array}{l}\text { tationary } \\
\text { that blasti } \\
\text { n is going } \\
\text { appen) }\end{array}$ & & $\begin{array}{l}\text { 2. Stationa } \\
\text { (Didn't notice t } \\
\text { blasting vibrat } \\
\text { going to hap }\end{array}$ & $\begin{array}{l}\text { at the } \\
\text { n is } \\
\text { n) }\end{array}$ & & $\begin{array}{l}\text { Study o } \\
\text { dn't not } \\
\text { the blas } \\
\text { ation is } \\
\text { happe }\end{array}$ & $\begin{array}{l}\text { r work } \\
\text { ice that } \\
\text { ting } \\
\text { going to } \\
\text { n) }\end{array}$ & $\begin{array}{l}\text { 4. Walk about } \\
\text { (Didn't notice } \\
\text { that the blasting } \\
\text { vibration is } \\
\text { going to } \\
\text { happen) }\end{array}$ & $\begin{array}{r}\text { 5. Run } \\
\text { (Didn't no } \\
\text { the blasting } \\
\text { is going to }\end{array}$ & $\begin{array}{l}\text { ning } \\
\text { tice that } \\
\text { vibration } \\
\text { happen) }\end{array}$ \\
\hline \multicolumn{11}{|c|}{ 5. The degree of inner pleasure } \\
\hline 1. Very & y unpleas & & 2. Not pleasar & & 3. $\mathrm{O}$ & linary & & 4. Pleasant & 5. Very $\mathrm{p}$ & leasant \\
\hline \multicolumn{11}{|c|}{ 6. Blasting vibration comfort } \\
\hline $\begin{array}{r}1 \\
\text { unco }\end{array}$ & $\begin{array}{l}\text { Very } \\
\text { mfortable }\end{array}$ & & 2. Uncomfortal & & 3. $\mathrm{O}$ & linary & & Comfortable & 5. Very col & nfortable \\
\hline
\end{tabular}


Residents living in buildings were influenced by various non-blasting vibration factors, such as blasting noise, environmental noise, environmental vibration and the activities they were engaged in. Those factors might influence the subjective feelings about blasting vibration comfort, to different degrees. In order to objectively evaluate the effects of various factors on comfort, Likert scale method was used in this paper to conduct survey and research. Likert scale was proposed by the social psychologist R. A. Likert from the United States [47], and can be used for individual or group surveys or evaluations. It has become a common practice in social survey [48-49]. Respondents were classified as local residents, construction technicians and residents for displacement and resettlement. The questionnaire that was provided to the respondents is shown in Table 2. First part of the questionnaire asked for some fundamental information of the respondents was collected, including gender, age, health condition, profession, educational background and whether they owned a house or not. Questions 1 to 5 mainly referred to the psychology, environment and ongoing activities of respondents. There were five evaluation indices in total, each with five rating levels. Question 6 was mainly about the subjective feelings regarding comfort and involved some complementary questions.

\section{Data analysis of the survey}

\subsection{Data processing of the survey}

Martin and Gentry [15] proposed mail survey or paper questionnaire. Before the survey, the meaning, purpose and concrete operating method was explained to each respondent. In order to encourage them to positively cooperate with the survey and protect for the instruments used for monitoring blasting vibration, each respondent was provided with some remuneration. Such an incentive was provided to increase the recovery rate of the questionnaire. In this study, nearby residents were provided with appropriate remuneration in the survey. Final collection showed that this method led to relatively ideal outcomes. In Area A, there were 260 questionnaires in total, and 101 valid questionnaires were retrieved. In Area B, there were 87 questionnaires in total, and 34 valid questionnaires were retrieved. In Area C, there were 31 questionnaires in total, and 14 valid questionnaires were retrieved. In Area D, there were 37 questionnaires in total, and 19 valid questionnaires were retrieved. Gentry and Martin [15] suggested a possible recovery rate of $10 \%-30 \%$ for such surveys, while the survey in this study obtained 168 groups of survey data in total, with a recovery rate of $40 \%$. Enough data were collected for the purpose of analysis, and relatively ideal results were obtained.

\subsection{Correlation of the survey data}

The correlation method is mainly used for studying the closeness of relationships between two variables. Correlation coefficient is generally used to indicate the degree of correlation between the variables, and its value ranges from -1 to 1 . The closer to 1 the absolute value of correlation coefficient, the higher is the degree of correlation between the variables; the closer to 0 the absolute value of correlation coefficient, the lower is the degree of correlation between variables. If the calculated correlation coefficient is greater than 0 , the two variables are positively correlated. On the contrary, a correlation coefficient less than 0 suggest a negative correlation between the two variables.

The methods used for calculating correlation coefficient include:

(1) Pearson correlation analysis

The formula for Pearson correlation analysis is:

$r_{X Y}=\frac{\sum_{i=1}^{N}\left(X_{i}-\bar{X}\right)\left(Y_{i}-\bar{Y}\right)}{\sqrt{\sum_{i=1}^{N}\left(X_{i}-\bar{X}\right)^{2} \cdot \sum_{i=1}^{N}\left(Y_{i}-\bar{Y}\right)^{2}}}$, 
where $X_{i}$ and $Y_{i}$ indicate the $i$ th values of variables $X$ and $Y$, respectively; and $\bar{X}$ and $\bar{Y}$ indicate the arithmetic mean values of variables $X$ and $Y$, respectively.

(2) Spearman correlation analysis

Spearman correlation analysis is based on the rank of data rather than their actual values. It is a non-parametric form of Pearson analysis, and the calculation method is shown as follows:

$$
r_{X Y}=\frac{\sum_{i=1}^{N}\left(R_{i}-\bar{R}\right)\left(S_{i}-\bar{S}\right)}{\sqrt{\sum_{i=1}^{N}\left(R_{i}-\bar{R}\right)^{2} \cdot\left(S_{i}-\bar{S}\right)^{2}}},
$$

where $R_{i}$ and $S_{i}$ represent the rank of variables $X$ and $Y$, respectively; and $\bar{R}$ and $\bar{S}$ represent the arithmetic mean values of variables $R_{i}$ and $S_{i}$, respectively.

Table 3. Average correlation coefficient of survey data

\begin{tabular}{|c|c|c|c|c|c|c|c|c|c|c|}
\hline Serial number & 1 & 2 & 3 & 4 & 5 & 6 & 7 & 8 & 9 & 10 \\
\hline Average correlation coefficient & 0.85 & 0.81 & 0.83 & 0.85 & 0.87 & 0.85 & 0.75 & 0.87 & 0.82 & 0.85 \\
\hline Serial number & 11 & 12 & 13 & 14 & 15 & 16 & 17 & 18 & 19 & 20 \\
\hline Average correlation coefficient & 0.82 & 0.84 & 0.83 & 0.78 & 0.85 & 0.77 & 0.87 & 0.77 & 0.80 & 0.83 \\
\hline Serial nt & 21 & 22 & 23 & 24 & 25 & 26 & 27 & 28 & 29 & 30 \\
\hline Average correlat & 0.84 & 0.72 & 0.65 & 0.69 & 0.81 & 0.82 & 0.84 & 0.80 & 0.85 & 0.78 \\
\hline Serial $\mathrm{n}$ & 31 & 32 & 33 & 34 & 35 & 36 & 37 & 38 & 39 & 40 \\
\hline Average corre & 0.77 & 0.80 & 0.67 & 0.76 & 0.80 & 0.81 & 0.69 & 0.77 & 0.79 & 0.72 \\
\hline Seri & 41 & 42 & 43 & 44 & 45 & 46 & 47 & 48 & 49 & 50 \\
\hline Average corr & 0.78 & 0.81 & 0.80 & 0.81 & 0.83 & 0.63 & 0.76 & 0.86 & 0.77 & 0.75 \\
\hline Seria & 51 & 52 & 53 & 54 & 55 & 56 & 57 & 58 & 59 & 60 \\
\hline Average corre & 0.78 & 0.76 & 0.75 & 0.84 & 0.69 & 0.83 & 0.83 & 0.78 & 0.80 & 0.77 \\
\hline Seri & 61 & 62 & 63 & 64 & 65 & 66 & 67 & 68 & 69 & 70 \\
\hline Average cor & 0.85 & 0.78 & 0.80 & 0.87 & 0.75 & 0.80 & 0.75 & 0.79 & 0.69 & 0.81 \\
\hline Seri & 71 & 72 & 73 & 74 & 75 & 76 & 77 & 78 & 79 & 80 \\
\hline Average corr & 0.82 & 0.85 & 0.75 & 0.85 & 0.84 & 0.80 & 0.81 & 0.87 & 0.86 & 0.86 \\
\hline Seri & 81 & 82 & 83 & 84 & 85 & 86 & 87 & 88 & 89 & 90 \\
\hline Average corl & 0.80 & 0.82 & 0.79 & 0.84 & 0.87 & 0.79 & 0.80 & 0.77 & 0.83 & 0.78 \\
\hline Seri & 91 & 92 & 93 & 94 & 95 & 96 & 97 & 98 & 99 & 100 \\
\hline Average corr & 0.80 & 0.80 & 0.80 & 0.77 & 0.79 & 0.80 & 0.78 & 0.82 & 0.85 & 0.82 \\
\hline Seri & 101 & 102 & 103 & 104 & 105 & 106 & 107 & 108 & 109 & 110 \\
\hline Average cor & 0.79 & 0.67 & 0.86 & 0.85 & 0.87 & 0.86 & 0.76 & 0.70 & 0.45 & 0.86 \\
\hline Seria & 111 & 112 & 113 & 114 & 115 & 116 & 117 & 118 & 119 & 120 \\
\hline cient & 0.82 & 0.76 & 0.80 & 0.83 & 0.79 & 0.80 & 0.48 & 0.77 & 0.75 & 0.76 \\
\hline Seri & 121 & 122 & 123 & 124 & 125 & 12 & 127 & 12 & 129 & 130 \\
\hline Average corr & 0.72 & 0.79 & 0.75 & 0.85 & 0.77 & 0.82 & 0.81 & 0.85 & 0.82 & 0.80 \\
\hline Seria & 131 & 132 & 133 & 134 & 135 & 136 & 137 & 138 & 139 & 140 \\
\hline Average corı & 0.78 & 0.78 & 0.79 & 0.85 & 0.79 & 0.83 & 0.77 & 0.83 & 0.79 & 0.82 \\
\hline Seri & 141 & 142 & 143 & 144 & 145 & 146 & 14 & 148 & 149 & 150 \\
\hline Average corr & 0.67 & 0.75 & 0.70 & 0.85 & 0.75 & 0.68 & 0.85 & 0.79 & 0.75 & 0.79 \\
\hline Seria & 151 & 152 & 153 & 154 & 155 & 156 & 157 & 158 & 159 & 160 \\
\hline Average correlation coefficient & 0.83 & 0.77 & 0.69 & 0.73 & 0.69 & 0.80 & 0.76 & 0.73 & 0.71 & 0.75 \\
\hline Seria & 161 & 162 & 163 & 164 & 165 & 166 & 167 & 168 & & \\
\hline Average corre & 0.72 & 0.68 & 0.79 & 0.77 & 0.81 & 0.78 & 0.71 & 0.83 & & \\
\hline
\end{tabular}

In the survey on blasting vibration comfort, the survey results could be affected by various external factors. In order to eliminate those disturbances and improve the reliability of survey results, data was checked for all obtained survey results, so as to discard those affected greatly. This paper considered Spearman correlation coefficient as the test indicator to check 168 groups 
of subjective evaluation results, and calculated the correlation coefficients between every two groups of data to obtain a $168 \times 168$ coefficient matrix. Arithmetic mean value was calculated for the correlation coefficient between every group of data and other groups, thus solving the average correlation coefficients, as shown in Table 3.

In statistics, as shown in Table 4, when the correlation coefficient is between 0.8 and 1.0 , it suggests that the variables are highly correlated; when it is between 0.5 and 0.8 , it suggests a moderate correlation. As shown in Fig. 4, the Spearman correlation coefficient between the 109th and 117 th groups of data were lower than 0.5 , which suggested a weak correlation. Through the above data checking, two groups of survey results (109 and 117) were removed and the rest 166 groups of data were reserved for further analysis.

Table 4. Judgment basis of variable correlation degree

\begin{tabular}{|c|c|c|c|c|}
\hline Correlation coefficient & $0-0.3$ & $0.3-0.5$ & $0.5-0.8$ & $0.8-1.0$ \\
\hline Correlation degree & Weak correlation & Low correlation & General correlation & High correlation \\
\hline
\end{tabular}

As mentioned above, the blasting vibration comfort was influenced by many factors, many of which might be mutually correlated, so correlation analysis was conducted for survey results. There were mainly two purposes for correlating the subjective evaluation of comfort with various factors, (i) to calculate the correlation coefficient between the subjective comfort value and various influencing factors and judge whether they were linearly correlated or exhibited a weak correlation, and (ii) to calculate the correlation between different influencing factors, so as to remove one or several of them from the list of correlated factors and avoid duplicate indices and unnecessary workload. Pearson correlation analysis was conducted on various influencing factors and the results were obtained as shown in Table 5. Table 5 shows that:

(1) The correlation coefficients between the pairs of subjective values of vibration comfort and blasting noise, environmental noise, environmental vibration and ongoing activities were between 0.28 and 0.34 , which are relatively low. Therefore, it was difficult to derive a subjective comfort function through regression analysis. The correlation coefficient of vibration comfort with the degree of mental pleasure was -0.01 , which indicated that the "degree of mental pleasure" index had a little effect on blasting vibration comfort. Similarly, the correlation between this index and other influencing factors was also very low, so this influencing factor was removed.

(2) The correlation coefficient between the peak velocity of blasting vibration and the absorbed energy index was 0.53 , which indicated that there was some correlation between them. The correlation coefficients of these two factors with the subjective feeling about comfort were -0.21 and -0.77 , respectively. Thus, the absorbed blasting vibration energy (ABVE) had a stronger correlation with comfort feeling than did the peak velocity of blasting vibration [46]. The "absorbed blasting vibration energy" evaluation index could be used to more objectively evaluate the influence of blasting vibration on human. It is superior in a way to the peak particle vibration velocity (PPV) index in representing the blasting vibration comfort.

(3) Both blasting vibration peak velocity and absorbed blasting vibration energy had negative correlation coefficients with other influencing factors and with the subjective feelings about human comfort. With an increase in blasting vibration peak velocity and absorbed blasting vibration energy, the subjective feeling of human was increasingly noticeable, as indicated by reduced comfort feeling. Different comfort feelings were assigned different values according to Table 2, so Likert value became smaller, which is consistent with the general law.

(4) The correlation coefficients between blasting noise, environmental noise, environmental vibration and ongoing activities were all less than 0.3 , which suggested a low correlation. This means that those factors were independent from each other and were not duplicated. They all had some correlation with the subjective feelings about blasting vibration comfort. Therefore, these four factors (and the absorbed blasting vibration energy evaluation index) were reserved as the five most influencing factors for the subjective evaluation of blasting vibration comfort. 
Table 5. The correlation coefficient between the factors

\begin{tabular}{|c|c|c|c|c|c|c|c|c|}
\hline & $\begin{array}{c}\text { Peak } \\
\text { particle } \\
\text { velocity }\end{array}$ & $\begin{array}{c}\text { Absorbed } \\
\text { blasting } \\
\text { vibration energy }\end{array}$ & $\begin{array}{c}\text { Blasti } \\
\text { ng } \\
\text { noise }\end{array}$ & $\begin{array}{c}\text { Environ } \\
\text { mental } \\
\text { noise }\end{array}$ & \begin{tabular}{|c} 
Environm \\
ent \\
vibration
\end{tabular} & $\begin{array}{c}\text { Ongoing } \\
\text { activitie } \\
\mathrm{s}\end{array}$ & $\begin{array}{l}\text { The degree } \\
\text { of inner } \\
\text { pleasure }\end{array}$ & $\begin{array}{l}\text { Blasting } \\
\text { vibration } \\
\text { comfort }\end{array}$ \\
\hline $\begin{array}{c}\text { Peak particle } \\
\text { velocity }\end{array}$ & 1.00 & & & & & & & \\
\hline $\begin{array}{c}\text { Absorbed } \\
\text { blasting } \\
\text { vibration energy }\end{array}$ & 0.53 & 1.00 & & & & & & \\
\hline Blasting noise & -0.18 & -0.29 & 1.00 & & & & & \\
\hline $\begin{array}{l}\text { Environmental } \\
\text { noise }\end{array}$ & -0.16 & -0.30 & 0.11 & 1.00 & & & & \\
\hline $\begin{array}{c}\text { Environment } \\
\text { vibration }\end{array}$ & -0.05 & -0.25 & 0.24 & 0.09 & 1.00 & & & \\
\hline $\begin{array}{l}\text { Ongoing } \\
\text { activities }\end{array}$ & -0.06 & -0.22 & 0.08 & 0.18 & 0.22 & 1.00 & & \\
\hline $\begin{array}{l}\text { The degree of } \\
\text { inner pleasure }\end{array}$ & 0.00 & 0.00 & 0.05 & -0.08 & 0.00 & 0.00 & 1.00 & \\
\hline $\begin{array}{c}\text { Blasting } \\
\text { vibration } \\
\text { comfort }\end{array}$ & -0.21 & -0.77 & 0.28 & 0.31 & 0.29 & 0.34 & -0.01 & 1.00 \\
\hline
\end{tabular}

\section{Statistical analysis on the survey data}

Through the reliability and correlation analysis on the data, two groups of survey data are removed, and five factors were identified as significantly influencing the subjective feeling about blasting vibration comfort. This section conducts statistical analysis on the reserved 166 groups of data and studies the similarities and differences in blasting vibration comfort among different population, as well as the influence of non-blasting vibration factors on comfort, including gender, age, health condition, profession, educational background and whether a respondent owns a house or not.

Statistical analysis was conducted on the comfort data of different areas, as shown in Table 6. The table shows that, in Area A and Area B, the average absorbed blasting vibration energies were relatively closer, i.e., both around $0.005 \mathrm{~cm}^{2} / \mathrm{s}^{2}$. But the average Likert value in Area B was greater than that in Area A, which indicated that the subjective comfort feeling of residents in Area B, on the whole, was superior to that of residents in Area A. The reason could be that Area A belonged to town districts, and the buildings there had three to four stories in general. Due to the elevation amplification effect in multi-story buildings, the blasting vibration actually experienced by humans in the buildings was stronger than that monitored in the foundation. In the rural Area B, the residences were relatively scattered, and the majority of them had one to two stories. On the whole, these two areas both had an average Likert value of greater than 3, suggesting that they could basically meet the comfort requirement. The average absorbed blasting vibration energies of Area C and Area D were markedly greater than those of Area A and Area B, both reaching to approximately $0.007 \mathrm{~cm}^{2} / \mathrm{s}^{2}$. However, their Likert values were 3.29 and 3.53, respectively, which suggested that residents in Area $\mathrm{C}$ and Area $\mathrm{D}$ had better comfort feelings than of residents in Area A and Area B. One reason is that residents in Area $\mathrm{C}$ were about to move and were not worried about the possible damage of blasting vibration to houses or buildings. Area D mainly comprised of hydropower station constructors who were not particularly worried about the failure of buildings and who were relatively experienced with blasting work. Accordingly, they were not significantly sensitive to blasting vibration and considered such vibration as tolerable.

Fig. 7 to Fig. 9 show the statistics of the distribution of Likert values over different areas, from which it can be seen that the residents' subjective feelings about blasting vibration comfort approximately obeyed normal distribution. "Very comfortable" and "very uncomfortable" were 
rarely reported, while "general" had the highest frequency of occurrence. This indicated that Pearson correlation analysis could be done on the survey data. The research results in this paper are similar to those obtained by other scholars [50]. For example, Griffin reported that the distribution of human feeling about vibration fails to reject normal distribution or logarithmic normal distribution.

Table 6. The average value of each survey area

\begin{tabular}{|l|c|c|c|c|}
\hline \multicolumn{1}{|c|}{ Survey area } & $\mathrm{A}$ & $\mathrm{B}$ & $\mathrm{C}$ & $\mathrm{D}$ \\
\hline Average absorbed blasting vibration energy (unit: $\mathrm{cm}^{2} / \mathrm{s}^{2}$ ) & 0.0052 & 0.0047 & 0.0070 & 0.0071 \\
\hline Average value of comfort & 3.16 & 3.28 & 3.29 & 3.53 \\
\hline Variance & 0.95 & 0.79 & 0.53 & 0.71 \\
\hline Mode & 3 & 3 & 4 & 4 \\
\hline Median & 3 & 3 & 3 & 4 \\
\hline
\end{tabular}

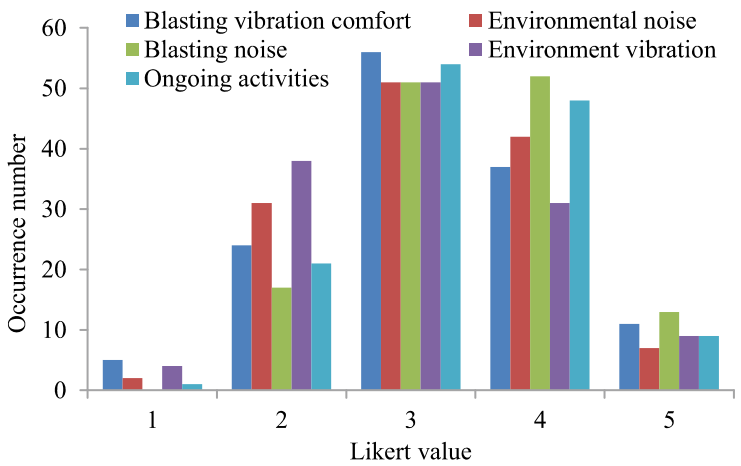

Fig. 7. Survey results of Area A and Area B

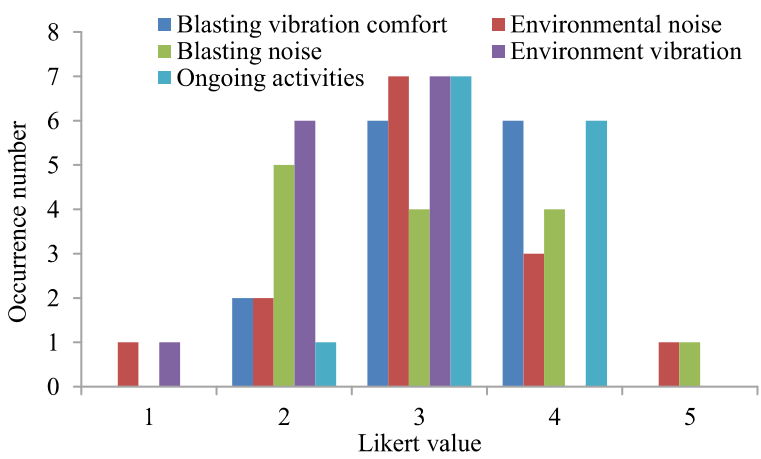

Fig. 8. Survey results of Area $C$

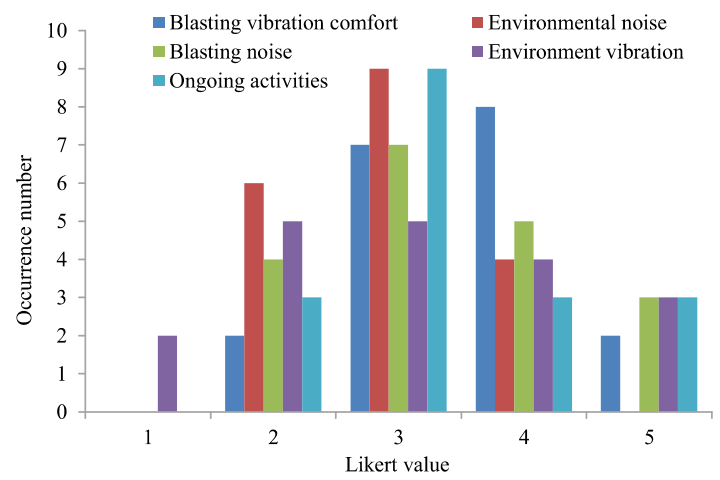

Fig. 9. Survey results of Area D 
Fig. 10 to Fig. 13 analyze the influence of factors, including age, gender, educational background and whether the respondent is a house owner or not, on subjective feeling about comfort. Fig. 10 showed that residents differing in age had different feelings about blasting vibration. With an increase in age from 20 to 60, residents had increased degree of uncomfortable subjective feelings, while those over 60 became less sensitive to blasting vibration. This indicates that middle-ages adults (between 30 and 50, especially those who had to take care of their families) were more worried about the blasting vibration effect. This research result is similar to that in Ref. [15]. From Fig. 11, respondents differing in gender in different areas had no significant difference in comfort feelings about blasting vibration. This means that gender did not exert too much influence on the subjective feelings about blasting vibration comfort. Fig. 12 shows that, those who had finished junior and high school education had stronger subjective reactions to blasting vibration, but on the whole, such difference was not significant. According to Fig. 13, the circumstances of the Likert values of comfort of constructors (Area $\mathrm{C}$ ) and residents about to move (Area D) were greater than 2 and occurred most frequently. However, for residents who were not about to move (Area A and Area B), the Likert values of comfort of 1 and 2 occurred relatively frequently. This indicates that the latter residents were more sensitive to blasting vibration, had worse comfort feelings than the former, and were quicker to complain. In summary, two factors, they are, age and whether the respondent is a house owner, were the two main factors that relatively significantly influenced comfort feelings.

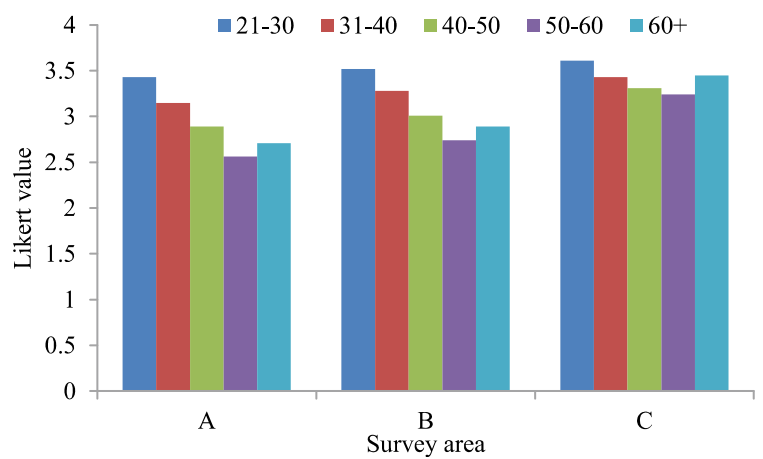

Fig. 10. Average comfort value of different age groups in Area A, B, C, respectively

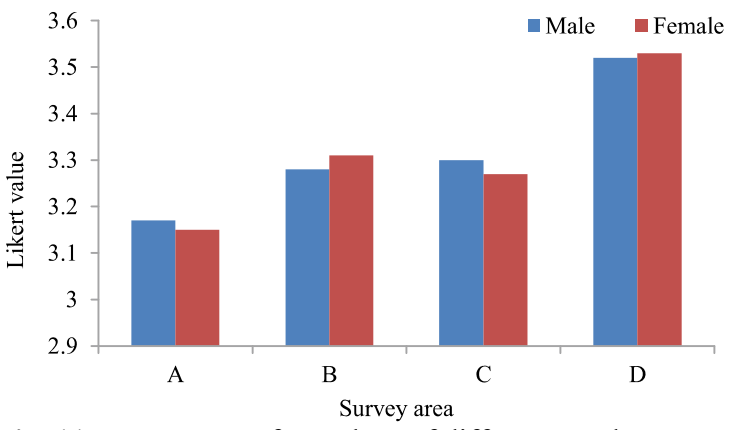

Fig. 11. Average comfort values of different gender groups

This section analyzed the similarities and differences in the subjective feelings about blasting vibration comfort on the part of different population, and compared the influences of several factors, including age, gender, educational background and whether the respondent is a house owner. Neither gender nor educational background exerted any significant influence, but age and whether the respondent is a house owner did exert a significant influence. Since the influence of age on comfort feelings was difficult to quantify, this paper conducted survey on the local majority residents, mostly aged between 20 and 50, which lies exactly in the age range with strong reactions. 
This method was employed to exactly fulfill the purpose of analyzing overall comfort. Therefore, six factors, including absorbed blasting vibration energy index, blasting noise, environmental noise, environmental vibration, ongoing activities and whether the respondent is a house owner, were finally determined as having relatively significant influences on blasting vibration comfort.

Engineering practice is often more concerned about the feelings of local residents (especially house owners) about blasting vibration. Therefore, based on the main influencing factors determined in this paper, the next step is to establish a multi-level and multi-factor comprehensive evaluation method to fulfill the purpose of quantitative assessment on blasting vibration comfort.

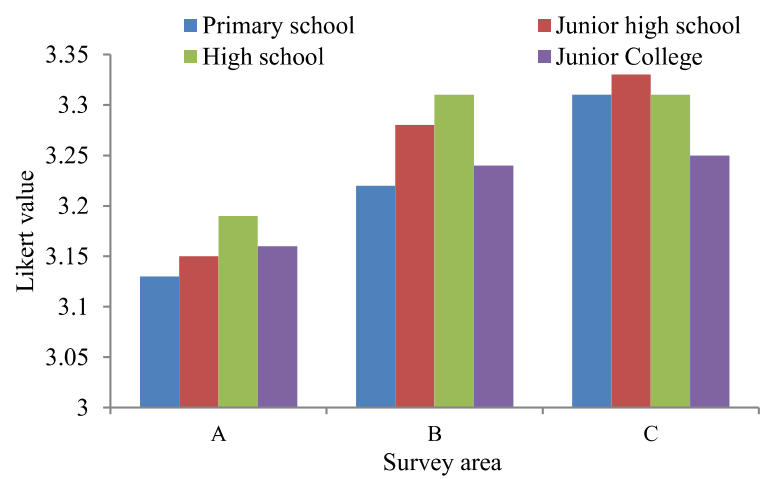

Fig. 12. Average values of the comfort degree of different education groups

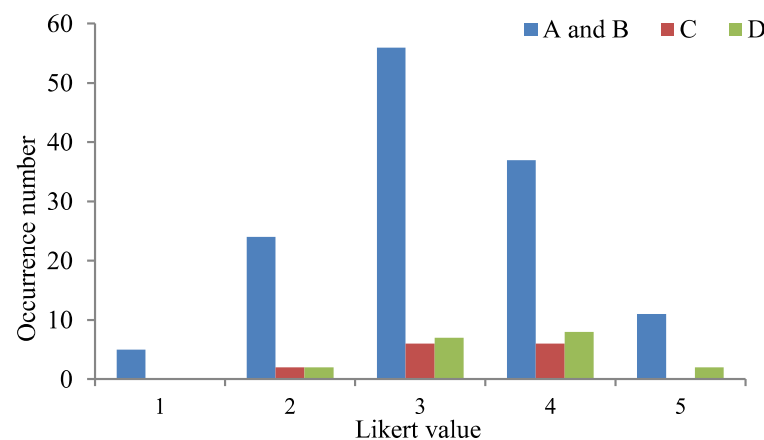

Fig. 13. The comfort value distribution of local residents and constructors

\section{Discussions}

As far as the traditional evaluation indices of blasting vibration comfort are concerned, such as the peak strength of blasting vibration and VDV, one of their disadvantages is the complicated calculation process or the insufficiency of factors considered. Peak intensity index is simple and easily obtained, but it neglects the influence of vibration frequency and duration. $K B_{F m a x}$ is essentially a frequency-weighted peak intensity index. VDV is not commonly used due to the difficulty to obtain the acceleration, though it considers many other factors. The allowable limits for all of them are set on the basis of statistical evaluations of the vibration levels. Another disadvantage is that blasting vibration characteristics, and building and human vibration characteristics cannot be combined closely, that is, they can only be used qualitatively rather than quantitatively to evaluate human comfort. In the previous research results of the authors, a linear-elastic vibration model was developed in which the effects of blasting vibration on the human body was considered as an energy transmission and conversion process, and proposed a comfort evaluation method of the human body ABVE. This method can be adopted to determine the magnitude of ABVE in various bands so as to realize a quantitative analysis of ABVE and frequency composition, and more effectively and accurately evaluate blasting vibration comfort 
effects. Moreover, through an energy transmission and conversion hypothesis, the blasting vibration, the building and the human body can be better linked together. In this paper, the authors conducted a number of surveys on blasting vibration comfort based on several blasting projects using the Likert scale method, and 168 groups of survey data were obtained. By data correlation analysis, the correlation between PPV, ABVE and the corresponding comfort values were studied. Studies have shown that the correlation coefficient between PPV and the ABVE index was 0.53, which indicated that there was some correlation between them. The correlation coefficients of these two factors with the subjective feeling about comfort were 0.21 and 0.77 , respectively. Thus, the ABVE index had a stronger correlation with comfort feeling than did the peak velocity of blasting vibration.

The other main disadvantage is that, even though blasting vibration factors (amplitude, frequency and duration) are easy to quantitatively analyze and provide various concrete evaluation indexes (PPV, VDV and so on), they do not have a certain linear relationship with blasting vibration comfort, due to the existence of fuzziness and uncertainties. Therefore, the traditional approaches cannot truly reflect human's real feelings by specifying certain comfort index thresholds. The reason for such fuzziness and uncertainties is that humans cannot classify the magnitude of vibration explicitly, and in addition to blasting vibration factors, human's feelings are influenced by many other factors. Since blasting vibration is different from mechanical vibration and poses a higher threat to safety, different people, under the influence of different attitudes, mental states, wealth levels, social environments and so forth, usually react differently to the same vibration effect. Blasting vibration comfort is related not only to the vibration characteristics of blasting and buildings, but also to the non-blasting factors such as, (i) the gender, age, income, psychology, and educational background of the subjects, (ii) the environment they are in, and (iii) the activities in which they are engaged. Moreover, when a certain value of an index is adopted as the threshold of comfort or discomfort, it only provides a qualitative evaluation, as it fails to differentiate the degree of discomfort among the public and also on the environment. In practical cases, due to vibration-induced earthquake and other negative effects (like blasting noise) as well as the involvement of several parties, quantitative analysis of blasting comfort is difficult. In this paper, survey and analysis were conducted on different factors influencing human subjective feelings. Through correlation and statistical analysis of data, six main influencing factors were determined, they are, absorbed blasting vibration energy index, blasting noise, environmental noise, environmental vibration, ongoing activities and whether the respondent is a house owner or not. This study showed that evaluation of subjective feeling about blasting vibration comfort is a multi-level and multi-factor problem. In the future study, the Fuzzy-AHP theory will be introduced and by establishing mathematical models, many influencing factors of the evaluation of blasting vibration comfort will be clarified and quantified to make them systematic and hierarchical. A comprehensive evaluation method based on FAHP will be proposed to evaluate and predict blasting vibration comfort feelings more comprehensively, objectively and quantitatively. The research results in this paper will provide a solid basis for establishing a multilevel and multi-factor comfort evaluation model.

\section{Conclusions}

As a subjective feeling, blasting vibration comfort is not only influenced by blasting vibration energy, but also correlated with non-blasting vibration factors including gender, age, income, psychology, educational background and environment. Based on a project case, this paper used Likert scale method to survey the blasting vibration comfort feelings of different population and obtained 168 groups of survey data in total. Correlation analysis method was adopted to calculate the correlation coefficients between various factors, to analyze the relative independence of each factor, and to correlate the factors with the subjective feelings about blasting vibration comfort. The similarities and differences in subjective feelings of different population were statistically analyzed. This study also compared the influences of factors including age, gender, educational 
background and whether the respondent is a house owner or not on the subjective comfort feelings. Neither gender nor educational background exerted a significant influence, but age and the status of house ownership did have a significant influence on the blasting vibration comfort. Finally, six main factors influencing the blasting vibration comfort were determined, they are, absorbed blasting vibration energy index, blasting noise, environmental noise, environmental vibration, ongoing activities and whether the status of house ownership. The research results in this paper are expected to provide a solid basis for establishing a multi-level and multi-factor comfort evaluation model.

\section{Acknowledgements}

This work is supported by the National Natural Science Foundation of China (No. 51009104), the National Science and Technology Support Program of China (No. 2014BAB03B00) and Young Teachers' Scientific Research Fund of Sichuan University (No. 2016SCU11039).

\section{References}

[1] Yan Y. F., Chen S. H., Zhang Q. H., et al. Research status and prospect of comforbaleness of blasting seismic effect. The Eleventh Session of the China Coal Society Blasting Academic Conference Papers Set, China Coal Society Blasting Professional Committee, Vol. 6, 2010, p. 14-20.

[2] Song Z. G., Bai Y., Jin W. L. Vibration serviceability analysis of buildings near the area of blasting operation. Journal of Vibration and Shock, Vol. 29, Issue 9, 2010, p. 129-133.

[3] Zhang Z. Y., Zhang W. X., Wu X. X. Modern Hydraulic Engineering Blasting. First Edition, China Water and Power Press, Beijing, 2003.

[4] Lucca F. J. Tight Construction Blasting: Ground Vibration Basics, Monitoring, and Prediction, 2003, http://saba.kntu.ac.ir/eecd/Ecourses/instrumentation/projects/reports/Seismic1/general/theory/tdconst vibration1.pdf.

[5] Schillinger R. R. Environmental effects of blast induced immissions. International Society of Explosives Engineers, Cleveland, OH, United States, 1996.

[6] Siskind D. E., Stagg M. S., Kopp J. W., et al. Structure Response and Damage Produced by Ground Vibration from Surface Mining Blasting. USBM RI8507, 1989.

[7] Egan J., Kermode J., Skyrman M., Turner L. L. Ground Vibration Monitoring for Construction Blasting in Urban Areas. Final Report, Caltrans, 2001, p. 1-11.

[8] Yao Q., Yang X. G., Li H. T., Research and prospect of the assessment methods of comfort due to blasting vibration. Journal of Vibration and Shock, Vol. 35, Issue 22, 2016, p. 152-160.

[9] Loeb J., Tannant D. D. Urban construction blasting in Canada-complaints and associated municipal bylaws. Civil Engineering and Architecture, Vol. 2, Issue 1, 2014, p. 1-10.

[10] Standard, Australian. AS 2187.2-2006. Explosives-Storage and Use, Part 2, 2006.

[11] Standard, British. BS 7385-2: Evaluation and Measurement for Vibration in Building: Part 2: Guide to Damage Levels from Ground Borne Vibration, 1993.

[12] Raina A. K., Haldar A., Chakraborty P. B., Choudhury M., Ramulu M. Human response to blast induced vibration and air overpressure: an Indian scenario. Bulletin of Engineering Geology and the Environment, Vol. 63, Issue 3, 2004, p. 209-214.

[13] Chen S., Zhang Z., Wu J. Human comfort evaluation criteria for blast planning. Environmental Earth Sciences, Vol. 74, Issue 4, 2015, p. 2919-2923.

[14] Yao Q., Yang X. G., Li H. T. Comparative analysis on the comfort assessment methods and standards of blasting vibration. Journal of Vibroengineering, Vol. 17, Issue 2, 2015, p. 1017-1036.

[15] Lusk B. An Analysis and Policy Implications of Comfort Levels of Diverse Constituents with Reported Units for Blast Vibrations and Limits: Closing the Communication Gap. Ph.D. Thesis, University of Missouri-Rolla, Missouri, USA, 2006.

[16] Petro A. J., Anderson D. A. Blast vibration problems: where do we go from here? Journal of Mines, Metals and Fuels, Vol. 34, Issue 11, 1986, p. 502-505.

[17] Spathis A. T., Brodbeck A. Future directions in ground vibration and airblast control within australian regulatory context. Proceedings of the Thirty-First Annual Conference on Explosives and Blasting Technique, International Society of Explosives Engineers, Cleveland, OH, 2005. p. 263-275. 
[18] Hustrulid W. Blasting Principles for Open Pit Mining. CRC Press, Balkema, Rotterdam, 1999, p. 269-292.

[19] Chiapetta F., Van Vreden A. Vibration/air blast controls, damage criteria, record keeping and dealing with complaints. 9th Annual BME Conference on Explosives, Drilling and Blasting Technology, The Institute of Quarrying, Southern Africa, Symposium, Durban, 2000.

[20] Kuzu C., Guclu E. The problem of human response to blast induced vibrations in tunnel construction and mitigation of vibration effects using cautious blasting in half-face blasting rounds. Tunnelling and Underground Space Technology, Vol. 24, Issue 1, 2009, p. 53-61.

[21] ISO 2631, Mechanical Vibration and Shock-Evaluation of Human Exposure to Whole-Body Vibration. Part 1: General Requirement. International Organization for Standardization (ISO), Geneva, Switzerland, 1997.

[22] ISO 2631, Mechanical Vibration and Shock-Evaluation of Human Exposure to Whole-Body Vibration. Part 2: Vibration in Buildings $(1 \mathrm{~Hz}$ to $80 \mathrm{~Hz}$ ). International Organization for Standardization (ISO), Geneva, Switzerland, 2003.

[23] Wang P., Lin L. A survey of study on vibration and evaluation of riding comfort for j-50 tractor. Scientia Silvae Sinicae, Vol. 34, Issue 4, 1998, p. 104-108.

[24] Parkin J., Sainte Cluque E. The impact of vibration on comfort and bodily stress while cycling. UTSG 46th Annual Conference, Newcastle University, 2014.

[25] Nakagawa C., Shimamaune R., Takami H., et al. Method of evaluating ride comfort reflecting passengers' subjective sensation to high frequency vibration. RTRI Report, Vol. 26, Issue 1, 2012.

[26] Kolich M., White P. L. Reliability and validity of a long term survey for automobile seat comfort. International Journal of Vehicle Design, Vol. 34, Issue 2, 2004, p. 158-167.

[27] Jiang Z., Streit D. A., El-Gindy M. Heavy vehicle ride comfort: Literature survey. International Journal of Heavy Vehicle Systems, Vol. 8, Issue 3, 2001, p. 258-284.

[28] Mohanan V., Sharma O., Singal S. P. A noise and vibration survey in an underground railway system. Applied Acoustics, Vol. 28, Issue 4, 1989, p. 263-275.

[29] Bhiwapurkar M. K., Singh P. P., Yadav J., et al. Influence of vibration on passenger comfort-A survey on Indian train. Proceedings of International Conference on Advances in Industrial Engineering Applications, Department of Industrial Engineering, Anna University Chennai, India, 2010.

[30] Johann F. A., Carlos M. E., Ricardo, F. L. Wind-induced motion on tall buildings: A comfort criteria overview. Journal of Wind Engineering and Industrial Aerodynamics, Vol. 142, 2015, p. 26-42.

[31] Schiavi A., Rossi L., Ruatta A. The perception of vibration in buildings: A historical literature review and some current progress. Building Acoustics, Vol. 23, Issue 1, 2016, p. 59-70.

[32] Lusk B., Hoffman J. M. Analysis of survey information about airblast and ground vibration reporting units. International Journal of Mining Reclamation and Environment, Vol. 25, Issue 2, 2011, p. 161-176.

[33] Lusk B., Worsey P. N. Correlation of public perception of blasting at rock quarries to reporting practices, public relations, and units of measurement used for regulations. Proceedings of the Third EFEE World Conference on Explosives and Blasting, UK, 2005, p. 55-63.

[34] Lusk B., Worsey P. N. Public perception of blasting at rock quarries in expanding urban environments - St. Charles, MO. Proceedings of the Thirty-First Annual Conference on Explosives and Blasting Technique, 2005, p. 251-262.

[35] Maeda S., Futatsuka M., Yonesaki J., et al. Relationship between questionnaire survey results of vibration complaints of wheelchair users and vibration transmissibility of manual wheelchair. Environmental Health and Preventive Medicine, Vol. 8, Issue 3, 2003, p. 82-89.

[36] Khan S., Sundström J. Vibration comfort in Swedish Inter-City trains - a survey on passenger posture and activities. Proceedings of the 17th International Conference in Acoustics (ICA), Japan, 2004, p. 3733-3736.

[37] Mirzaei R., Mohammadi M. Survey of vibration exposure and musculoskeletal disorder of Zahedan city tractor drivers by nordics questionnaire. International Journal of Occupational Hygiene, Vol. 2, Issue 2, 2010, p. 46-50.

[38] Rudenko D. An analytical approach for diagnosing and solving blasting complaints. Journal of Explosives Engineering, Vol. 19, Issue 4, 2002, p. 36-41.

[39] Siebert H. L. Perceptions of the use of explosives in urban areas. Proceedings of the 11th Conference on Explosives and Blasting Technique, 1985, p. 111-123.

[40] Singh P. K., Vogt W., Singh R. B. Singh D. P. Blasting side effects - investigations in an opencast coal mine in India. Journal of Surface Mining Reclamation and Environment, The Netherlands, Vol. 10, 1996, p. 155-159. 
[41] Deros B. M., Daruis D. D. I., Nor M. J. M. Evaluation of car seat using reliable and valid vehicle seat discomfort survey. Industrial Engineeering and Management Systems, Vol. 8, Issue 2, 2009, p. $121-130$.

[42] Hendron A. J., Oriard L. L. Specification for controlled blasting and civil engineering projects. Proceedings of North American Rapid Excavation and Tunneling Conference, Vol. 12, Issue 2, 1972, p. 62-64.

[43] Frontczak M, Wargocki P. Literature survey on how different factors influence human comfort in indoor environments. Building and Environment, Vol. 46, Issue 4, 2011, p. 922-937.

[44] Yao Q., Yang X. G., Li H. T. A method for evaluating the comfort during blasting vibration based on energy absorbing principle. Journal of Vibration and Control, 2017, https://doi.org/10.1177/1077546316685680.

[45] Walonick, D. S. Everything you wanted to know about questionnaires but were afraid to ask. http://www.statpac.com/research-papers/questionnaires.htm, 2006.

[46] Walonick, D. S. Guidelines for customer satisfaction surveys and employee opinion surveys, http://www.statpac.com/customer-satisfaction.htm, 2006.

[47] Feng X. T. Questionnaire Design in Social Survey. Second Edition, Tianjin People's Publishing Press, Tianjin, 2002.

[48] Ke H. X., Huang J. H., Shen H. Statistical Analysis in Investigation Study. Third Edition, Beijing Broadcasting Institute Press, Beijing, 2015.

[49] Fan K. X. The Quantitative Method of Sociology. First Edition, Nanjing University Press, Nanjing, 2004.

[50] Tu R. H., Fang D. Q., Zhan J. K., et al. Evaluation of community response to environmental vibration: the principle of fuzzy probability. China Environmental Science, Vol. 10, Issue 5, 1990, p. $356-359$.

\section{Appendix}

Table A1. Survey results of subjective feeling to blasting vibration comfort

\begin{tabular}{|c|c|c|c|c|c|c|c|c|c|}
\hline Num. & $\begin{array}{c}\text { Survey } \\
\text { area }\end{array}$ & \begin{tabular}{|c|}
$\mathrm{PPV}$ \\
$(\mathrm{cm} / \mathrm{s})$
\end{tabular} & $\begin{array}{l}\mathrm{ABVE} \\
\left(\mathrm{cm}^{2} / \mathrm{s}^{2}\right)\end{array}$ & $\begin{array}{c}\text { Blasting } \\
\text { noise }\end{array}$ & $\begin{array}{c}\text { Environmental } \\
\text { noise }\end{array}$ & $\begin{array}{c}\text { Environmental } \\
\text { vibration }\end{array}$ & $\begin{array}{l}\text { Ongoing } \\
\text { activities }\end{array}$ & $\begin{array}{c}\text { Degree of inner } \\
\text { pleasure }\end{array}$ & Comfort \\
\hline 1 & & 0.121 & 0.0045 & 3 & 4 & 3 & 4 & 3 & 3 \\
\hline 2 & & 0.146 & 0.0043 & 4 & 3 & 4 & 2 & 4 & 3 \\
\hline 3 & & 0.154 & 0.0078 & 4 & 4 & 4 & 4 & 3 & 2 \\
\hline 4 & & 0.1 & 0.0021 & 4 & 4 & 2 & 4 & 5 & 4 \\
\hline 5 & & 0.227 & 0.0087 & 3 & 3 & 4 & 3 & 3 & 2 \\
\hline 6 & & 0.133 & 0.0071 & 4 & 4 & 4 & 4 & 3 & 2 \\
\hline 7 & & 0.167 & 0.0061 & 3 & 3 & 3 & 3 & 2 & 3 \\
\hline 8 & & 0.067 & 0.0016 & 4 & 4 & 1 & 4 & 3 & 5 \\
\hline 9 & & 0.047 & 0.0009 & 2 & 2 & 4 & 2 & 2 & 4 \\
\hline 10 & & 0.181 & 0.0065 & 4 & 3 & 3 & 2 & 4 & 3 \\
\hline 11 & & 0.267 & 0.0088 & 3 & 3 & 4 & 3 & 3 & 2 \\
\hline 12 & & 0.027 & 0.0004 & 2 & 4 & 3 & 3 & 3 & 4 \\
\hline 13 & & 0.125 & 0.0048 & 3 & 3 & 4 & 3 & 2 & 3 \\
\hline 14 & Area A & \begin{tabular}{|l|}
0.102 \\
\end{tabular} & 0.0041 & 4 & 3 & 3 & 4 & 2 & 3 \\
\hline 15 & & \begin{tabular}{|l|}
0.125 \\
\end{tabular} & 0.0049 & 3 & 2 & 2 & 2 & 3 & 4 \\
\hline 16 & & 0.217 & 0.0067 & 3 & 3 & 3 & 2 & 3 & 3 \\
\hline 17 & & 0.08 & 0.0007 & 1 & 2 & 2 & 1 & 4 & 5 \\
\hline 18 & & 0.417 & 0.0096 & 2 & 4 & 4 & 2 & 4 & 2 \\
\hline 19 & & 0.207 & 0.0088 & 2 & 4 & 4 & 3 & 3 & 2 \\
\hline 20 & & 0.138 & 0.0051 & 4 & 4 & 3 & 3 & 4 & 3 \\
\hline 21 & & 0.07 & 0.0008 & 3 & 4 & 3 & 4 & 3 & 5 \\
\hline 22 & & 0.156 & 0.0039 & 3 & 5 & 2 & 4 & 2 & 3 \\
\hline 23 & & 0.337 & 0.0083 & 2 & 4 & 3 & 1 & 4 & 2 \\
\hline 24 & & 0.476 & 0.0119 & 2 & 1 & 1 & 2 & 1 & 1 \\
\hline 25 & & 0.207 & 0.0037 & 4 & 3 & 5 & 3 & 4 & 4 \\
\hline 26 & & 0.138 & 0.0046 & 4 & 4 & 2 & 3 & 3 & 3 \\
\hline 27 & & 0.156 & 0.0052 & 3 & 3 & 3 & 3 & 2 & 3 \\
\hline
\end{tabular}




\begin{tabular}{|c|c|c|c|c|c|c|c|c|}
\hline 28 & 0.178 & 0.0048 & 4 & 2 & 3 & 2 & 3 & 3 \\
\hline 29 & \begin{tabular}{|l|}
0.189 \\
\end{tabular} & 0.0027 & 3 & 4 & 3 & 3 & 4 & 4 \\
\hline 30 & 0.128 & 0.0006 & 3 & 5 & 2 & 4 & 4 & 5 \\
\hline 31 & 0.224 & 0.0037 & 5 & 3 & 3 & 4 & 2 & 4 \\
\hline 32 & \begin{tabular}{|l|}
0.099 \\
\end{tabular} & 0.0089 & 4 & 3 & 3 & 2 & 3 & 2 \\
\hline 33 & \begin{tabular}{|l|}
0.121 \\
\end{tabular} & 0.0114 & 3 & 3 & 4 & 4 & 1 & 1 \\
\hline 34 & 0.227 & 0.0095 & 2 & 3 & 3 & 2 & 4 & 2 \\
\hline 35 & 0.283 & 0.0052 & 3 & 2 & 3 & 2 & 4 & 3 \\
\hline 36 & 0.218 & 0.0134 & 3 & 4 & 3 & 3 & 4 & 1 \\
\hline 37 & \begin{tabular}{|l|}
0.178 \\
\end{tabular} & 0.0076 & 4 & 4 & 4 & 2 & 4 & 2 \\
\hline 38 & \begin{tabular}{|l|}
0.189 \\
\end{tabular} & 0.0018 & 3 & 2 & 3 & 4 & 3 & 4 \\
\hline 39 & 0.228 & 0.0014 & 3 & 2 & 3 & 4 & 5 & 5 \\
\hline 40 & 0.587 & 0.0147 & 4 & 4 & 3 & 3 & 3 & 1 \\
\hline 41 & 0.337 & 0.0094 & 5 & 3 & 3 & 4 & 5 & 2 \\
\hline 42 & 0.332 & 0.0081 & 2 & 3 & 2 & 3 & 2 & 2 \\
\hline 43 & 0.132 & 0.0073 & 3 & 2 & 2 & 3 & 4 & 2 \\
\hline 44 & 0.235 & 0.0067 & 3 & 2 & 3 & 3 & 2 & 2 \\
\hline 45 & \begin{tabular}{|l|}
0.32 \\
\end{tabular} & 0.0053 & 3 & 3 & 4 & 4 & 3 & 3 \\
\hline 46 & 0.098 & 0.0038 & 2 & 3 & 2 & 3 & 5 & 3 \\
\hline 47 & 0.156 & 0.0025 & 2 & 4 & 2 & 4 & 3 & 4 \\
\hline 48 & 0.144 & 0.0033 & 4 & 4 & 4 & 3 & 4 & 4 \\
\hline 49 & 0.207 & 0.0018 & 3 & 5 & 5 & 4 & 3 & 5 \\
\hline 50 & 0.138 & 0.0073 & 2 & 2 & 3 & 2 & 4 & 2 \\
\hline 51 & \begin{tabular}{|l|}
0.08 \\
\end{tabular} & 0.0027 & 4 & 4 & 4 & 3 & 2 & 4 \\
\hline 52 & 0.156 & 0.0051 & 4 & 2 & 5 & 4 & 3 & 3 \\
\hline 53 & 0.178 & 0.0061 & 2 & 2 & 3 & 2 & 4 & 2 \\
\hline 54 & \begin{tabular}{|l|}
0.189 \\
\end{tabular} & 0.0026 & 5 & 4 & 3 & 3 & 5 & 4 \\
\hline 55 & 0.228 & 0.0029 & 4 & 3 & 4 & 3 & 1 & 4 \\
\hline 56 & 0.224 & 0.0065 & 3 & 4 & 2 & 3 & 3 & 3 \\
\hline 57 & \begin{tabular}{|l|}
0.219 \\
\end{tabular} & 0.0088 & 2 & 3 & 2 & 3 & 3 & 2 \\
\hline 58 & 0.241 & 0.0034 & 5 & 3 & 5 & 3 & 3 & 4 \\
\hline 59 & 0.227 & 0.0038 & 4 & 3 & 3 & 3 & 2 & 4 \\
\hline 60 & 0.283 & 0.0061 & 2 & 4 & 2 & 4 & 4 & 3 \\
\hline 61 & \begin{tabular}{|l|}
0.218 \\
\end{tabular} & 0.0029 & 4 & 3 & 4 & 3 & 4 & 4 \\
\hline 62 & \begin{tabular}{|l|}
0.1 \\
\end{tabular} & 0.0047 & 2 & 4 & 3 & 5 & 4 & 3 \\
\hline 63 & 0.121 & 0.0057 & 3 & 3 & 4 & 2 & 4 & 3 \\
\hline 64 & 0.146 & 0.0056 & 4 & 3 & 3 & 3 & 4 & 3 \\
\hline 65 & 0.081 & 0.0048 & 5 & 4 & 2 & 2 & 5 & 3 \\
\hline 66 & \begin{tabular}{|l|}
0.098 \\
\end{tabular} & 0.0051 & 3 & 3 & 1 & 3 & 3 & 3 \\
\hline 67 & \begin{tabular}{|l|}
0.134 \\
\end{tabular} & 0.0008 & 4 & 5 & 3 & 5 & 2 & 5 \\
\hline 68 & 0.088 & 0.0039 & 4 & 3 & 5 & 3 & 3 & 4 \\
\hline 69 & 0.171 & 0.0033 & 3 & 4 & 4 & 4 & 1 & 4 \\
\hline 70 & \begin{tabular}{|l|}
0.046 \\
\end{tabular} & 0.0019 & 5 & 3 & 4 & 5 & 3 & 4 \\
\hline 71 & 0.201 & 0.0067 & 3 & 2 & 2 & 4 & 3 & 3 \\
\hline 72 & 0.101 & 0.0046 & 3 & 3 & 2 & 3 & 4 & 3 \\
\hline 73 & 0.186 & 0.0052 & 3 & 4 & 4 & 5 & 2 & 3 \\
\hline 74 & 0.105 & 0.0018 & 3 & 3 & 4 & 4 & 4 & 4 \\
\hline 75 & 0.121 & 0.0067 & 2 & 3 & 2 & 3 & 3 & 3 \\
\hline 76 & 0.126 & 0.0058 & 3 & 3 & 2 & 3 & 5 & 3 \\
\hline 77 & 0.081 & 0.0037 & 4 & 2 & 2 & 3 & 4 & 3 \\
\hline 78 & 0.098 & 0.0029 & 4 & 4 & 4 & 5 & 4 & 4 \\
\hline 79 & \begin{tabular}{|l|}
0.074 \\
\end{tabular} & 0.0014 & 4 & 4 & 3 & 3 & 4 & 4 \\
\hline 80 & 0.162 & 0.0065 & 3 & 3 & 3 & 4 & 4 & 3 \\
\hline 81 & \begin{tabular}{|l|}
0.253 \\
\end{tabular} & 0.0052 & 4 & 2 & 3 & 4 & 5 & 3 \\
\hline 82 & 0.125 & 0.0034 & 5 & 3 & 2 & 4 & 4 & 4 \\
\hline
\end{tabular}




\begin{tabular}{|c|c|c|c|c|c|c|c|c|c|}
\hline 83 & & 0.102 & 0.0076 & 3 & 3 & 5 & 4 & 5 & 3 \\
\hline 84 & & 0.125 & \begin{tabular}{|l|}
0.0078 \\
\end{tabular} & 3 & 3 & 3 & 3 & 2 & 3 \\
\hline 85 & & 0.113 & \begin{tabular}{|l|}
0.0054 \\
\end{tabular} & 4 & 3 & 3 & 4 & 4 & 3 \\
\hline 86 & & 0.155 & 0.0147 & 3 & 2 & 3 & 4 & 4 & 1 \\
\hline 87 & & \begin{tabular}{|l|}
0.034 \\
\end{tabular} & 0.0044 & 3 & 4 & 3 & 3 & 2 & 3 \\
\hline 88 & & \begin{tabular}{|l|}
0.18 \\
\end{tabular} & \begin{tabular}{|l|}
0.0081 \\
\end{tabular} & 4 & 4 & 2 & 4 & 2 & 3 \\
\hline 89 & & 0.139 & 0.0073 & 5 & 3 & 3 & 4 & 5 & 3 \\
\hline 90 & & 0.177 & 0.0067 & 4 & 3 & 3 & 2 & 5 & 3 \\
\hline 91 & & 0.123 & 0.0053 & 3 & 2 & 3 & 4 & 4 & 2 \\
\hline 92 & & 0.205 & 0.0048 & 3 & 4 & 3 & 3 & 2 & 3 \\
\hline 93 & & 0.125 & 0.0053 & 4 & 2 & 3 & 3 & 5 & 3 \\
\hline 94 & & 0.102 & 0.0078 & 5 & 2 & 2 & 3 & 4 & 3 \\
\hline 95 & & 0.125 & 0.0073 & 3 & 2 & 3 & 4 & 5 & 3 \\
\hline 96 & & 0.083 & 0.0027 & 3 & 3 & 2 & 4 & 5 & 4 \\
\hline 97 & & 0.055 & 0.0011 & 4 & 4 & 4 & 5 & 2 & 4 \\
\hline 98 & & 0.034 & 0.0021 & 4 & 2 & 4 & 4 & 5 & 4 \\
\hline 99 & & 0.042 & 0.0016 & 4 & 3 & 3 & 4 & 5 & 4 \\
\hline 100 & & 0.032 & 0.0019 & 3 & 4 & 2 & 3 & 4 & 4 \\
\hline 101 & & 0.065 & 0.0015 & 4 & 3 & 5 & 5 & 3 & 5 \\
\hline 102 & \multirow{34}{*}{ - } & 0.09 & 0.0018 & 4 & 3 & 2 & 2 & 1 & 4 \\
\hline 103 & & 0.033 & 0.0014 & 4 & 3 & 3 & 4 & 5 & 4 \\
\hline 104 & & 0.074 & 0.0008 & 4 & 4 & 4 & 3 & 5 & 5 \\
\hline 105 & & \begin{tabular}{|l|}
0.155 \\
\end{tabular} & \begin{tabular}{|l|}
0.0061 \\
\end{tabular} & 3 & 3 & 3 & 3 & 4 & 3 \\
\hline 106 & & 0.069 & 0.0019 & 4 & 4 & 4 & 4 & 3 & 4 \\
\hline 107 & & \begin{tabular}{|l|}
0.174 \\
\end{tabular} & 0.0087 & 2 & 2 & 4 & 4 & 4 & 3 \\
\hline 108 & & 0.086 & 0.0047 & 4 & 1 & 2 & 2 & 2 & 3 \\
\hline 109 & & 0.615 & 0.0156 & 1 & 1 & 4 & 3 & 3 & 1 \\
\hline 110 & & \begin{tabular}{|l|}
0.247 \\
\end{tabular} & 0.0018 & 4 & 3 & 4 & 4 & 5 & 3 \\
\hline 111 & & 0.296 & 0.0051 & 3 & 4 & 2 & 3 & 4 & 3 \\
\hline 112 & & 0.361 & 0.0068 & 4 & 3 & 2 & 2 & 2 & 3 \\
\hline 113 & & \begin{tabular}{|l|l|}
0.156 \\
\end{tabular} & 0.0039 & 2 & 2 & 3 & 3 & 2 & 2 \\
\hline 114 & & 0.144 & 0.0083 & 3 & 3 & 3 & 4 & 3 & 3 \\
\hline 115 & & 0.207 & 0.0047 & 2 & 3 & 4 & 3 & 3 & 3 \\
\hline 116 & & \begin{tabular}{|l|l|}
0.138 \\
\end{tabular} & 0.0051 & 4 & 5 & 3 & 3 & 3 & 3 \\
\hline 117 & & \begin{tabular}{|l|}
0.08 \\
\end{tabular} & 0.0061 & 1 & 5 & 3 & 2 & 2 & 2 \\
\hline 118 & & 0.156 & 0.0066 & 2 & 3 & 3 & 3 & 5 & 3 \\
\hline 119 & & 0.178 & 0.0039 & 3 & 5 & 3 & 4 & 2 & 4 \\
\hline 120 & & \begin{tabular}{|l|l}
0.189 \\
\end{tabular} & 0.0065 & 4 & 2 & 3 & 3 & 5 & 2 \\
\hline 121 & & 0.228 & 0.0088 & 3 & 4 & 1 & 4 & 3 & 2 \\
\hline 122 & & \begin{tabular}{|l|}
0.224 \\
\end{tabular} & 0.0074 & 3 & 4 & 2 & 3 & 5 & 3 \\
\hline 123 & & 0.219 & 0.0058 & 5 & 4 & 2 & 2 & 4 & 3 \\
\hline 124 & & 0.241 & 0.0061 & 3 & 4 & 4 & 4 & 5 & 4 \\
\hline 125 & & \begin{tabular}{|l|}
0.227 \\
\end{tabular} & 0.0049 & 4 & 2 & 2 & 3 & 5 & 3 \\
\hline 126 & & \begin{tabular}{|l|}
0.1 \\
\end{tabular} & 0.0027 & 3 & 2 & 3 & 4 & 4 & 4 \\
\hline 127 & & \begin{tabular}{|l|}
0.121 \\
\end{tabular} & 0.0007 & 4 & 4 & 4 & 3 & 3 & 5 \\
\hline 128 & & \begin{tabular}{|l|}
0.146 \\
\end{tabular} & 0.0036 & 4 & 3 & 4 & 4 & 3 & 4 \\
\hline 129 & & 0.081 & 0.0038 & 5 & 3 & 4 & 4 & 3 & 3 \\
\hline 130 & & 0.098 & 0.0041 & 3 & 5 & 5 & 4 & 5 & 3 \\
\hline 131 & & 0.134 & 0.0068 & 3 & 2 & 2 & 2 & 4 & 2 \\
\hline 132 & & 0.125 & 0.0059 & 5 & 3 & 4 & 3 & 4 & 2 \\
\hline 133 & & 0.113 & 0.0083 & 3 & 2 & 1 & 3 & 3 & 2 \\
\hline 134 & & 0.055 & 0.0019 & 4 & 4 & 3 & 3 & 3 & 4 \\
\hline 135 & & 0.034 & \begin{tabular}{|l|}
0.0007 \\
\end{tabular} & 3 & 4 & 4 & 3 & 3 & 5 \\
\hline 136 & \multirow{2}{*}{ Area C } & 0.22 & 0.0046 & 5 & 3 & 3 & 3 & 4 & 4 \\
\hline 137 & & 0.3 & 0.0052 & 2 & 4 & 2 & 4 & 4 & 3 \\
\hline
\end{tabular}




\begin{tabular}{|c|c|c|c|c|c|c|c|c|c|}
\hline 138 & & 0.39 & 0.0048 & 4 & 3 & 2 & 4 & 4 & 4 \\
\hline 139 & & 0.2 & 0.0051 & 2 & 3 & 2 & 3 & 3 & 4 \\
\hline 140 & & 0.14 & 0.0061 & 4 & 5 & 2 & 4 & 4 & 4 \\
\hline 141 & & 1.19 & 0.0166 & 3 & 1 & 3 & 3 & 4 & 2 \\
\hline 142 & & 0.31 & 0.0069 & 2 & 2 & 2 & 3 & 4 & 4 \\
\hline 143 & & 0.52 & 0.0065 & 3 & 3 & 2 & 2 & 1 & 3 \\
\hline 144 & & 0.66 & 0.0088 & 4 & 3 & 3 & 4 & 3 & 3 \\
\hline 145 & & 1.03 & 0.0074 & 3 & 4 & 3 & 3 & 5 & 2 \\
\hline 146 & & 0.68 & 0.0058 & 2 & 2 & 1 & 4 & 4 & 3 \\
\hline 147 & & 0.25 & 0.0061 & 3 & 3 & 3 & 3 & 3 & 4 \\
\hline 148 & & 0.45 & 0.0049 & 4 & 4 & 3 & 3 & 2 & 3 \\
\hline 149 & & 0.78 & 0.0097 & 2 & 3 & 3 & 4 & 2 & 3 \\
\hline 150 & \multirow{19}{*}{ Area D } & 0.52 & 0.0058 & 4 & 3 & 3 & 3 & 2 & 4 \\
\hline 151 & & 0.48 & 0.0037 & 5 & 4 & 4 & 5 & 3 & 4 \\
\hline 152 & & 0.25 & 0.0089 & 3 & 3 & 2 & 5 & 4 & 5 \\
\hline 153 & & 0.66 & 0.0074 & 2 & 3 & 3 & 5 & 2 & 4 \\
\hline 154 & & 0.68 & 0.0065 & 2 & 4 & 2 & 2 & 3 & 3 \\
\hline 155 & & 0.15 & 0.0032 & 5 & 3 & 4 & 2 & 2 & 5 \\
\hline 156 & & 0.78 & 0.0034 & 4 & 3 & 5 & 3 & 4 & 4 \\
\hline 157 & & 0.82 & 0.0076 & 4 & 3 & 2 & 2 & 3 & 4 \\
\hline 158 & & 0.55 & 0.0078 & 4 & 4 & 1 & 3 & 5 & 3 \\
\hline 159 & & 0.33 & 0.0054 & 2 & 2 & 2 & 3 & 5 & 4 \\
\hline 160 & & 0.58 & 0.0047 & 3 & 2 & 5 & 4 & 4 & 3 \\
\hline 161 & & 0.82 & 0.0074 & 4 & 2 & 1 & 3 & 4 & 3 \\
\hline 162 & & 0.91 & 0.0081 & 2 & 2 & 3 & 3 & 5 & 2 \\
\hline 163 & & 0.78 & 0.0073 & 3 & 4 & 3 & 5 & 3 & 3 \\
\hline 164 & & 1.18 & 0.0136 & 3 & 3 & 2 & 3 & 4 & 2 \\
\hline 165 & & 1.07 & 0.0109 & 3 & 3 & 4 & 3 & 3 & 4 \\
\hline 166 & & 0.43 & 0.0055 & 5 & 2 & 3 & 4 & 3 & 4 \\
\hline 167 & & 1.06 & 0.0098 & 3 & 2 & 5 & 4 & 3 & 3 \\
\hline 168 & & 0.83 & 0.0074 & 3 & 3 & 4 & 3 & 4 & 3 \\
\hline
\end{tabular}

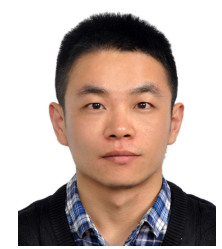

Qiang Yao received the B.E. degree in Water Conservancy and Hydropower Engineering from Sichuan University, China, in 2010 and his Ph.D. degree in Hydraulic Structure Engineering from Sichuan University, China, in 2015, respectively. Presently he is a Lecturer in College of Water Conservancy and Hydropower, Sichuan University. His research interests include hydraulic structure engineering, blasting engineering, rock dynamics, vibration comfort and construction of water conservancy project.

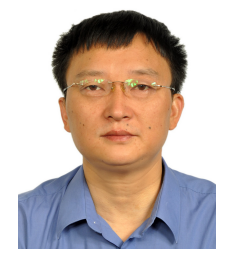

Xingguo Yang received the B.E. degree in Water Conservancy and Hydropower Engineering from Sichuan University, China, in 1991, and his M.A. and Ph.D. degrees in Hydraulic Structure Engineering from Sichuan University, China, in 1998 and 2008, respectively. Presently he is a Professor in College of Water Conservancy and Hydropower, Sichuan University. Presently he is particularly interested in earthquake lake disposal, blasting engineering, water conservancy project construction, and geotechnical engineering calculation.

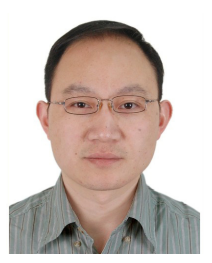

Hongtao Li received the B.E. degree in Water Conservancy and Hydropower Engineering from Wuhan University, China, in 2001, and his M.A. and Ph.D. degrees in Hydraulic Structure Engineering from Wuhan University, China, in 2004 and 2007, respectively. Presently he is a Professor in College of Water Conservancy and Hydropower, Sichuan University. His research interests include blasting engineering, rock dynamics, and numerical simulation of geotechnical engineering and construction of water conservancy project. 